\title{
The Internal stress and binding force of carbon nanotubes/ Pb-Sn
}

\section{composite coatings}

\author{
Zhengxi Hu1,a, Xiaohua Jie 2,b \\ ( ${ }^{1}$ Hezhou University, Hezhou Guangxi 542899 China; ${ }^{2}$ Faculty of Material and Energy, Guang \\ dong University of Technology, Guangzhou 510006) \\ a huzhengxi588193@126.com bjiexh@scnu.edu.cn
}

Key words: $\mathrm{Pb}-\mathrm{Sn}$ electroplating solution, carbon nanotubes(CNTs), Internal stress, binding force Abstract: Multi-walled carbon nanotube (MWCNT)/Pb-Sn composite coatings and $\mathrm{Pb}-\mathrm{Sn}$ alloy coatings were prepared by electrodeposition technique, respectively. The Internal stress of the coatings was studied through changed the Process parameters and the binding force of the coatings were compared through Thermal shock experiment. The morphology images of the $\mathrm{Pb}$-Sn coatings and $\mathrm{Pb}-\mathrm{Sn}$ composite coatings were observed by $\mathrm{SEM}$, it shows that the $\mathrm{Pb}-\mathrm{Sn}$ composite coating has a lower binding force than the $\mathrm{Pb}-\mathrm{Sn}$ coating. This was mainly about the uniform distribution of MWCNT in the coatings, thereby reducing the internal stress.

\section{Introduction}

Composite electro-deposition technique as a new technology in materials surface science has made great progress in recent years. Composite coatings has better wear resistance, corrosion resistance and heat resistance properties than matrix material and been used widely in industry equipments.

Since discovered by Iijima in 1991, carbon nanotubes(CNTs) have been actively and widely studied. They are believed to be ideal reinforcing phase for making advanced composites due to their remarkable mechanical properties, such as exceptionally high elastic modulus, large elastic strain and fracture strain sustaining capability [1-4]. Numerous researches into composites which include metal-CNTs [5-10] have been actively pursued.

In particular, multi-walled carbon nanotubes, with the concentric hollow structure of enclosed surface graphite cylinders, have the privileged self-lubricating properties [11]. If the CNTs were used as nano-reinforcements and were added into other materials, the mechanics and wear properties of the composite materials would be improved greatly [12-14].

In the electro-deposition process, most metal coatings have with internal stress. The internal stress of the coatings often causes the substrate to deform or crack, and even result in the coating peeling off. Not only has it affected the function of the coatings, but also adverse the substrate. The reason for the internal stress caused by the electroplating layer is still lack of comprehensive and in-depth research yet; the study of the internal stress of the coating on binding force, corrosion resistance and coating brittleness is of great significance. Therefore, this paper compared the influence of different factors on the internal stress of carbon nanotube lead-tin composite coating, and tested the binding force of the coatings, in order to seek the excellent preparation method of the high-quality composite coatings. 


\section{Experimental}

Sample preparation

The MWCNTs used are commercially available (Shenzhen Nanotech Port Co., Ltd. China), have specific diameter of $60-100 \mathrm{~nm}$, length of $5-15 \mu \mathrm{m}$ and the purity is greater than $95 \%$. Dispersing nanotubes homogeneously in bath is crucial. They were mixed by a mixed acid $(98 \%$ sulfuric acids and $68 \%$ nitric acids, $3: 1$ ) in a round-bottomed flask, and the mixture had been refluxed at $80{ }^{\circ} \mathrm{C}$ for 120 minutes in order to remove impurities and open some agglomerates of MWCNTs, then the mixture was filtrated and washed with deionized water until $\mathrm{pH}$ value reached 7 , these acid-treated MWCNTs were put into $\mathrm{Pb}-\mathrm{Sn}$ electroplating bath, which had the following composition: $\mathrm{Pb}$ $\left(\mathrm{BF}_{4}\right)_{2} \quad 80 \mathrm{gL}-1, \mathrm{Sn}\left(\mathrm{BF}_{4}\right) 20 \mathrm{gL}^{-1}, \mathrm{HBF}_{4} 160 \mathrm{gL}^{-1}, \mathrm{H}_{3} \mathrm{BO}_{3} 25 \mathrm{gL}^{-1}$, Hydroquinone $1 \mathrm{gL}^{-1}$ and Polyacrylic acid $3 \mathrm{mlL}^{-1}$ as dispersant.

The cathode was copper plates with the dimension $20 \times 30 \times 0.6 \mathrm{~mm}$, which were polished by sanding in advance and thereafter ultrasonic cleaning to wipe off the surface grease before electrodepositing. A lead plate (purity of 99.98 mass \%) was used as an anode. Magnetic force agitation was utilized for 60 minutes thereafter ultrasonic agitation for 30 minutes in bath before electro-deposition. The optimal current density of electrodepositing was $2 \mathrm{Adm}^{-2}$ according to a Hull cell test. The electrodepositing was carried out while the ultrasonic agitation worked all along.

Cathode bending method

The internal stress can be measured by the thin film cathodic bending method [15]. As shown in Figure 1, the cathode was made of $40 \mathrm{~mm} \times 20 \mathrm{~mm} \times 0.5 \mathrm{~mm}$ copper. The copper sheet was annealed at $350^{\circ} \mathrm{C}$ for 1 hour before the test to eliminate the internal stress of the copper sheet itself. The copper surface would be seriously oxidized after annealing, It is necessary to use dilute acid to erase oxide film. Dilute acid solution: $\mathrm{H}_{2} \mathrm{SO}_{4}: 40 \mathrm{~g} / \mathrm{L} ; \mathrm{HCl} 150 \mathrm{~g} / \mathrm{L}$. after cleaning, dry and static pressure to flatten, the back was sealed with PVC electrical tape, so that the back was insulation. The distance between the anode and the anode was $5 \mathrm{~cm}$, the upper part of the anode and the cathode were fixed with clip, and keep the constant distance as $5 \mathrm{~cm}$. A one-liter beaker was used as plating tank, the plating time was 2 hours, the thickness of the coating was measured, the offset at the lower part of the cathode was measured, and then the internal stress was calculated by the following formula:

$$
\begin{aligned}
& S=\frac{1}{3} \frac{E t^{2} Z^{\prime}}{d L^{2}} \\
& \left.S \_ \text {Coating stress ( } \mathrm{Pa}\right) \text {; } \\
& \text { E-Matrix material elastic modulus ( } \mathrm{Pa}) \text {; } \\
& t \text { __ Cathode base thickness ( } \mathrm{mm}) \text {; } \\
& Z^{\prime} \_ \text {Cathode lower offset }(\mathrm{mm}) \text {; } \\
& d \text { Coating thickness }(\mathrm{mm}) \text {; } \\
& L \text { _ The length of the cathode ( } \mathrm{mm}) \text {; }
\end{aligned}
$$



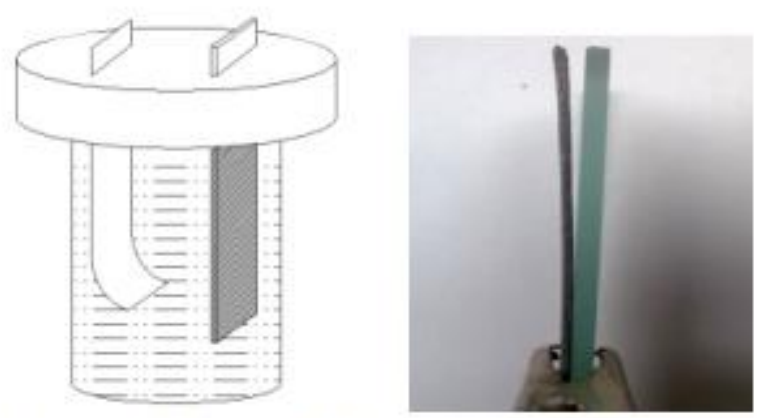

Fig. 1 Schematic diagram of internal stress

Thermal shock experiment

The lead-tin alloy coating hardness is low. Thermal shock method is generally used to measure qualitatively the adhesion of the coatings in the course of production. The current density was maintained at $2 \mathrm{~A} / \mathrm{dm}^{2}$ and the bath temperature were maintained at $15^{\circ} \mathrm{C}$, Five pieces of a tin-tin alloy coating sample were prepared. the content of carbon nanotubes in the bath was $2 \mathrm{~g} / \mathrm{L}$, the current density was $2 \mathrm{~A} / \mathrm{dm}^{2}$, and bath temperature was $15^{\circ} \mathrm{C}$, Five pieces of composite coating sample were prepared also.

The lead-tin alloy coating and the carbon nanotube lead-tin composite coating samples were placed in the CS101 type electric blast drying oven respectively. After holding for $30 \mathrm{~S}$ at $150^{\circ} \mathrm{C}$, then they were placed in the cold water for $10 \mathrm{~S}$, the hot and cold alternating was defined as a thermal shock cycle. The two group samples were conducted for 30 cycles of thermal shock test.

\section{Results and Discussions}

Effect of Current Density on Internal Stress of Coating

When the plating solution content was $2 \mathrm{~g} / \mathrm{L}$, the current densities were $1 \mathrm{~A} / \mathrm{dm}^{2}, 2 \mathrm{~A} / \mathrm{dm}^{2}, 3 \mathrm{~A} /$ $\mathrm{dm}^{2}$ and $4 \mathrm{~A} / \mathrm{dm}^{2}$, the bath temperature was at $15^{\circ} \mathrm{C}$, internal stress with current density in composite coating. The internal stress of the composite coatings was shown in Fig. 2 respectively. It can be concluded that the internal stress increased with the increase of the current density.

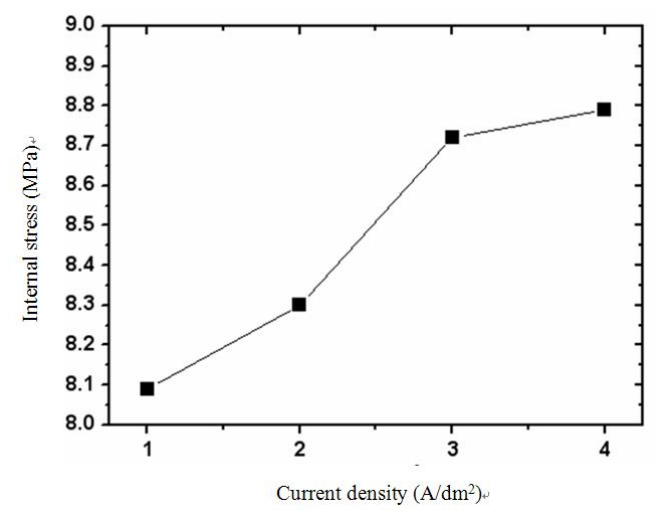

Fig. 2 The effect of bath temperature on internal stress

effect of temperature on the internal stress of coatings

When the content of carbon nanotubes in the bath was $2 \mathrm{~g} / \mathrm{L}$ and the current density was $2 \mathrm{~A} / \mathrm{dm}^{2}$, the temperature of the bath was changed. The internal stress were measured at $10^{\circ} \mathrm{C}, 15^{\circ} \mathrm{C}$ and $20^{\circ} \mathrm{C}$ 
stress. The internal stress of the composite coatings is shown in Fig. 3. It is seen that as the temperature of the bath increased the internal stress tended to decrease gradually.

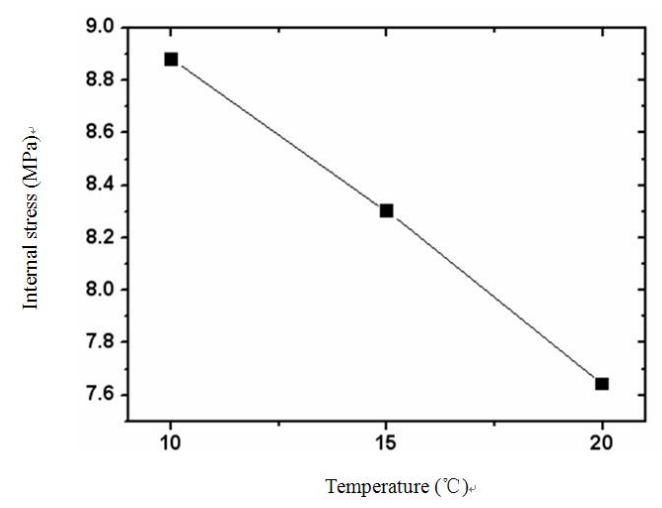

Fig. 3 The effect of temperature on the internal stress of coatings

appearances of samples after thermal shock experiment

For the tin-tin alloy coating, as shown in the left of Fig. 4, the edge of the coating was found to be bubbling and partially falling off, and the coating was blackened seriously, and Any bubbling and shedding was not found in the lead-tin composite coatings after 30 cycles of thermal shock, as shown in the right of Fig4. It can be concluded that that the composite coating has the better binding force than the lead-tin alloy coatings. The binding force of lead-tin alloy can meet the needs of the actual practice application, the interface between the coating and the substrate, the crack is not easy to form and expand. The thermal shock experiment showed that the composite coatings met the production needs.

The addition of carbon nanotubes increases the density of the coatings. When the content of carbon nanotubes in the bath is $2 \mathrm{~g} / \mathrm{L}$, the internal stress is greatly reduced, and the binding force of the composite coating decrease and crack source of the formation are reduced. Thereby the bubble and fall off reduce when the coatings in the thermal shock experiment. On the other hand, the addition of suitable carbon nanotube content under a reasonable plating process parameter minimizes the internal stress of the coating; it is difficulty for micro cracks to spread. Thus, the composite coatings also exhibit better binding effect.

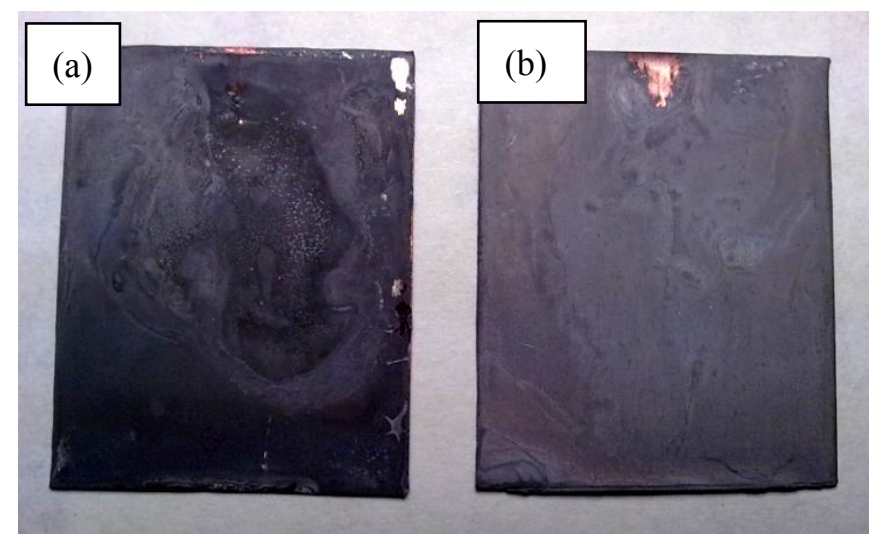

Fig.4 The appearance of $\mathrm{Pb}-\mathrm{Sn}$ coatings(a) and $\mathrm{Pb}-\mathrm{Sn}-\mathrm{CNTs}$ composite coatings(b) after thermal shock

Fig 5 (a) and Fig 5 (b) are micrograph of lead-tin alloy coating and composite coating respectively. Ordinary lead-tin alloy coating is relatively loose, and the composite coating of the 
organization is relatively dense, it is due to the electrolyte in the plating solution after ionization, the surface of carbon Nan tubes deposited with metal atoms, so that the overall carbon Nan tubes coatings is preferable. When the intrinsic stress exists in the composite coating, the carbon Nan tubes play a stress transfer and uniform effect role, thus reducing the possible stress concentration in the composite coating, it lead to the internal stress decreased.

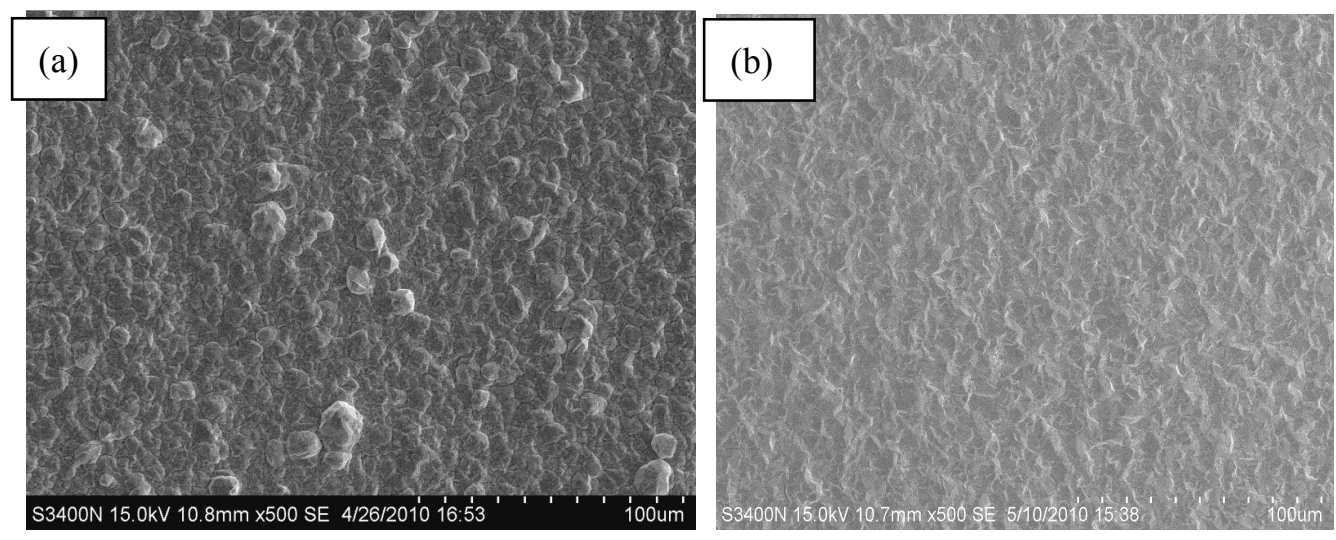

Fig 5 SEM images of $\mathrm{Pb}-\mathrm{Sn}$ coatings(a) and $\mathrm{Pb}-\mathrm{Sn}-\mathrm{CNTs}$ composite coatings(b)

\section{Conclusions}

(1) The influence of current density on the internal stress of the composite coatings was studied by catholic bending method. The content of carbon Nan tubes in the bath was $2 \mathrm{~g} / \mathrm{L}$, the current densities were $1 \mathrm{~A} / \mathrm{dm}^{2}, 2 \mathrm{~A} / \mathrm{dm}^{2}, 3 \mathrm{~A} / \mathrm{dm}^{2}$ and $4 \mathrm{~A} / \mathrm{dm}^{2}$, when the bath temperature is constant at $15^{\circ} \mathrm{C}$, the internal stress of the composite coating increased gradually with the current density increasing.

(2) When the content of carbon nanotubes in the bath was $2 \mathrm{~g} / \mathrm{L}$ and the current density was $2 \mathrm{~A} / \mathrm{dm}^{2}$, with the temperature of the bath increasing, and the internal stress of the composite coating tends to decrease gradually by bending cathode method.

(3) Thermal shock experiment showed that the $\mathrm{Pb}-\mathrm{Sn}$ composite coating has a lower binding force than the $\mathrm{Pb}-\mathrm{Sn}$ alloy coating. This was mainly about the uniform distribution of carbon Nan tubes in the coatings, thereby reducing the internal stress.

\section{Acknowledgments}

This work was supported by Guang-xi Higher Education Undergraduate Teaching Reform Project (Grant No.2015JGA360)

\section{References}

[1] M.M.J. Treacy, T.W. Ebbesen, T.M. Gibson, Nature 381 (1996) 680.

[2] E.W.Wong, P.E. Sheehan, C.M. Lieber, Science 277 (1997) 1971.

[3] D.A. Walters, L.M. Ericson, M.J. Casavant, J. Liu, D.T. Colbert, K.A. Smith, Appl. Phys. Lett. 74 (1999) 3803.

[4] M.F. Yu, O. Lourie, M. Dyer, K. Moloni, T. Kelly, Science 287 (2000) 637.

[5]X.H.Chen,F.Q.Cheng,S.L.Li,Li.P.Zhou,D.Y.Li. Surface and coatings technology 155(2002)274-278.

[6] W.X. Chen, J.P. Tu, L.Y. Wang, H.Y. Gan, Z.D. Xu, X.B. Zhang, Carbon 41 (2003)215-222. 
[7] W.X. Chen, J.P. Tu, Z.D. Xu,W.L. Chen, X.B. Zhang, D.H. Cheng. Mater. Lett. 57 (2003) 1256-1260.

[8]X.H.Chen,C.S.Chen,H.N.Xiao,H.B.Liu,L.P.Zhou,S.L.Li et al. Tribol. Int. 39 (2006)22-28.

[9] Z.H. Li, X.Q. Wang, M. Wang, F.F. Wang, H.L. Ge, Tribol. Int. 39 (2006) 953-957.

[10] J. Tan, T. Yu, B. Xu, Q. Yao. Tribol. Lett. 21 (2006) 107-111.

[11] Z.H. Li, X.Q. Wang, M. Wang, F.F. Wang, H.L. Ge, Tribol. Int. 39 (2006) 953-957.

[12] Yang Z, Dong B, Huang Y, Liu L, Yan FY, Li HL. A study on carbon nanotubes reinforced poly(methyl methacrylate) nanocomposites. Mater. Lett. 2005;59:2128.

[13] Xia Z, Riester L, Curtin WA, Li H, Sheldon BW, Liang J, Chang B,Xu JM. Direct observation of toughening mechanisms in carbon nanotube ceramic matrix composites. Acta Mater. 2004;52:931.

[14]Ogasawara T, Ishida Y, Ishikawa T, Yokota R. Characterization of multi-walled carbon nanotube/phenylethynyl terminated polyimide composites. Compos.: Part A 2004;35:67.

[15]Zeng Hua Liang, Wu Zhongda, Qin Yuewen, etc. Electroplating process manual [M]. Beijing: Machinery Industry Press. 2002, $758 \sim 759$. 